\title{
H. Pylori is related to osteoporosis but only in premenopausal female: a cross-sectional study
}

\author{
Jing-Wei Wang ${ }^{1}$, Feng-Xiao Dong ${ }^{1}$, Hui Su', Licun Zhu', Sujun Shao ${ }^{2}$ and Hong Liu ${ }^{3^{*}}$ (D)
}

\begin{abstract}
Background: Recently, an increasing number of studies have focused on the extra-gastrointestinal effects of Helicobacter pylori (H. pylori), including metabolic syndrome, fatty liver, and rheumatic and skin diseases. Osteoporosis is an asymptomatic disease that can eventually lead to fractures and has a significant impact on the quality of life of elderly individuals. Sex is an influential factor that plays a crucial role in the development of osteoporosis. The aim of this study was to investigate the relationship between $\mathrm{H}$. pylori infection and osteoporosis and to identify potential influencing factors.

Methods: We conducted a cross-sectional study of individuals older than 50 years old, who had undergone regular physical examinations at the Beijing Shijitan Hospital Health Examination Center from July to October 2018. We evaluated the associations of osteopenia and osteoporosis with $\mathrm{H}$. pylori infection and related serum markers by using multiple linear regression and logistic regression. Then, we analysed the correlation between sex and potential serum biomarkers.
\end{abstract}

Results: There were significant relationships between $\mathrm{H}$. pylori infection status and bone density in premenopausal females but not in males $(P=0.381)$ according to Fisher's exact test. In females, $H$. pylori positivity $(\mathrm{OR}=0.132, P=$ 0.023), Body Mass Index (BMI) $(\mathrm{OR}=28.163, P=0.021)$, and homocysteine $(\mathrm{HCY})(\mathrm{OR}=17.218, P=0.045)$ were associated with osteoporosis. Calcium had a trend but no statistically significant $(\mathrm{OR}=0.060, P=0.076)$ relationship with osteoporosis. Furthermore, the waist-to-hip ratio $(\mathrm{OR}=5.783, P=0.029), \mathrm{BMI}(\mathrm{OR}=0.152, P=0.014)$ and triglyceride levels $(\mathrm{OR}=0.201, P=0.036)$ were significantly different by sex, after adjusting for age as a confounder.

Conclusion: $\mathrm{H}$. pylori positivity, BMI and HCY are associated with osteoporosis in premenopausal females. Chronic inflammation may be involved in the relationship between $\mathrm{H}$. pylori and osteoporosis.

Keywords: Female, H. Pylori infection, Osteoporosis, Premenopausal, Chronic inflammation

\section{Background}

Helicobacter pylori (H. pylori), a gram-negative, spiralshaped microaerophilic bacterium, has been shown to be an important pathogen in gastrointestinal diseases [1]. Approximately $50 \%$ of the world population has been

\footnotetext{
* Correspondence: maggie19950426@163.com

${ }^{3}$ Department of Gastroenterology, Beijing Shijitan Hospital, Capital Medical University Beijing, Beijing 100038, China

Full list of author information is available at the end of the article
}

affected by $\mathrm{H}$. pylori, and approximately 800 million Chinese individuals are affected by this disease. It may cause chronic inflammation of the gastric mucosa, which may lead to chronic atrophic gastritis, peptic ulcer diseases, and gastric cancer [2, 3]. Moreover, the latest reports have described the investigation of the extragastrointestinal effects of $\mathrm{H}$. pylori, including metabolic syndrome [4], fatty liver [5], and rheumatic and skin diseases [6]. These parenteral diseases associated with $\mathrm{H}$.

C C The Author(s). 2020 Open Access This article is licensed under a Creative Commons Attribution 4.0 International License, which permits use, sharing, adaptation, distribution and reproduction in any medium or format, as long as you give appropriate credit to the original author(s) and the source, provide a link to the Creative Commons licence, and indicate if changes were made. The images or other third party material in this article are included in the article's Creative Commons licence, unless indicated otherwise in a credit line to the material. If material is not included in the article's Creative Commons licence and your intended use is not permitted by statutory regulation or exceeds the permitted use, you will need to obtain permission directly from the copyright holder. To view a copy of this licence, visit http://creativecommons.org/licenses/by/4.0/ The Creative Commons Public Domain Dedication waiver (http://creativecommons.org/publicdomain/zero/1.0/) applies to the data made available in this article, unless otherwise stated in a credit line to the data. 
pylori infection seriously affect the patient's general condition and cause a series of complications.

Osteoporosis is an asymptomatic disease characterized by a decreased density of normally mineralized bone that usually occurs in elderly persons. It has been reported that approximately 2 million men and 8 million women over the age of 50 in the United States have been diagnosed with osteoporosis, with an estimated 34 million suffering from osteopenia [7]. In the development of osteoporosis, there is often a long latent period before the appearance of the main clinical manifestation: pathologic fractures. Moreover, the most prevalent sequelae of osteoporosis are compression fractures of the vertebral bodies and fractures of the ribs, proximal femurs, humeri, and distal radiuses, which could have a significant impact on the quality of life of elderly individuals. Therefore, the prevention and early detection of osteoporosis is particularly important for the elderly population.

A majority of studies support the idea that at any given age, women have a higher risk of fracture than men [8]. However, men tend to have worse outcomes after fracture than women: they are twice as likely to die after a hip fracture than women [9]. Moreover, sexrelated factors remain unclear. Therefore, exploring the differences in factors influencing osteoporosis in males and females will be helpful to explore the pathogenesis of osteoporosis and early prevention of its occurrence and development.

There are some well-established risk factors for the emergence of osteoporosis, such as age, sex, body mass index, and alcohol consumption [10]. Recent articles have focused on $\mathrm{H}$. pylori and osteoporosis. Different researchers have proposed different theories, including but not limited to, inflammation induced by $\mathrm{H}$. pylori infection [11] and malabsorption of nutrients [12, 13]. However, there is still a lack of systematic data analyses on the relationship between $\mathrm{H}$. pylori and osteoporosis. The association between osteoporosis and $\mathrm{H}$. pylori has been studied by many Japanese scientists and remains controversial. In addition, there are still some deficiencies in existing research. Few studies have focused on the correlation between $\mathrm{H}$. pylori and osteoporosis in Chinese premenopausal females. The sample sizes have been insufficient, there is a lack of investigations on the influence of sex, and there is a lack of sufficient serum markers. The aim of this study was to investigate the relationship between $\mathrm{H}$. pylori and osteoporosis and to identify potential influencing factors.

\section{Methods}

\section{Study population}

Briefly, men and women, older than 50 years old (i.e., not including those aged 50 years old), who had regular physical examinations at the Beijing Shijitan Hospital Health Examination Center from July to October 2018 were included. Our research used the following exclusion criteria for the data collection periods: (1) patients using the following drugs and having comorbidities that may cause secondary osteosis: glucocorticoids, thyroid/ parathyroid drugs, psychotropic drugs, anticonvulsants, selective estrogen receptor modulators (SERMs), vitamin $\mathrm{D}$, calcium, and bisphosphonate; (2) patients who had a history of gastrectomy, inflammatory bowel disease, malignant diseases, chronic kidney disease, diabetes mellitus, hypo/hyperthyroidism, hypo/hyperparathyroid disorder, acromegaly and rheumatoid arthritis (including collagen disease). Study participants who had been diagnosed with $\mathrm{H}$. pylori infection before or had potentially anti-H. pylori drugs in the past 1 month were recruited as well.

We also excluded postmenopausal women in the present study. The criteria for determining menopause, based on the latest guidelines, included any of the following: (1) prior bilateral oophorectomy; (2) age $\geq 60$ years old; (3) age $<60$ years and amenorrhoeic for 12 or more months in the absence of chemotherapy, tamoxifen, or toremifene [14]. The female study participants were not pregnant or lactating.

\section{Data collection}

Among all the eligible individuals, 228 eligible study participants gave informed verbal consent and provided their basic information, including demographics (age, sex, race), smoking status, and medicine use. All ethics approvals were given by the Ethics Committee of Beijing Shijitan Hospital affiliated with Capital Medical University, and the study was performed in accordance with the Declaration of Helsinki. Blood measurements were performed with fresh serum obtained after a 12-h fast to minimize the confounding effects of diurnal variation on hormone concentrations and included tests for glucose metabolism, liver function, renal function, lipid metabolism, ions (calcium, iron), tumour markers, pepsinogen (PG), and progastrin-releasing peptide (proGRP). Anthropometric measurements, including waist circumference $(\mathrm{cm})$, blood pressure $(\mathrm{mmHg})$, body weight $(\mathrm{kg})$ and height $(\mathrm{cm})$, were measured by trained nurses using a standardized protocol. Diastolic and systolic blood pressure were measured in the morning. Body mass index (BMI) was calculated by taking a person's weight in kilograms divided by their height in metres squared. The waist-to-hip ratio (WHR) is measured as waist circumference divided by hip circumference. $\mathrm{H}$. pylori infection status was measured by a [13]C breathing test on the same day with an empty stomach. Tumour markers were measured using enzyme-linked immunosorbent assay methods. 


\section{Diagnosis of osteoporosis}

The bone mineral density (BMD) of lumbar vertebrae 2-4 (L2-4) was measured by DXA using a Discovery DXA system (Hologic, Bedford, Massachusetts). The results provided BMD $(\mathrm{g} / \mathrm{cm} 2)$ and young adult mean bone mineral density. The diagnosis of osteoporosis was performed in accordance with the World Health Organization diagnostic criteria from the World Health Organization (WHO) Collaborating Center for Metabolic Bone Diseases [15]. A value for BMD within one standard deviation (SD) of the average BMD of normal adults was regarded as normal. Osteopenia is defined as a BMD that lies between 1 and 2.5 standard deviations below the young adult mean value. BMD more than 2.5 SD below the young adult mean value was classified as osteoporosis [15].

\section{Statistical analyses}

We used SPSS statistical software version 22.0 for data analyses. Continuous variables were reported as means \pm standard deviations, whereas categorical variables were presented as percentages. Study subjects were first classified into three groups according to BMD classification: normal, osteopenia, and osteoporosis. The KolmogorovSmirnov test was used to verify whether the data fit a normal distribution, and all continuous variables that did not conform to a normal distribution underwent transformation for analysis. Summary and grouping data for baseline characteristics (the laboratory examination) were compared using a $t$ test for continuous variables and Fisher's exact test for categorical variables in the $\mathrm{H}$. pylori- and H. pylori+ groups. Moreover, we divided the study population by sex and used Fisher's exact test to verify whether there were sex differences in the relationship between $\mathrm{H}$. pylori and osteoporosis.

Multivariate-adjusted odds ratios (ORs) and 95\% confidence intervals (CIs) were calculated using logistic regression among the three subgroups. To further analyse the relationship between $\mathrm{H}$. pylori infection status and osteoporosis, we created a model using total cholesterol (TC), triglycerides (TG), uric acid (UA), BMI, WHR, low-density lipoprotein cholesterol (LDL-C), C-reactive protein $(\mathrm{CRP})$, homocysteine $(\mathrm{HCY}), \mathrm{H}$. pylori infection status, calcium $(\mathrm{Ca})$, vitamin $\mathrm{B} 12$ and the BMD groups that analysed the different sexes separately. The study population's high-density lipoprotein cholesterol (HDLC) and glucose levels were all normal, so we did not include them in the model.

Meanwhile, we analysed the differences in markers between males and females. We separated the study population according to sex and further analysed the patients' basic data in the same way as we analysed the baseline characteristics. We further analysed the relationship between sex and markers to find sex differences in the relationship between $\mathrm{H}$. pylori infection and osteoporosis. The markers included TC, LDL-C, UA, TG, glucose (GLU), CA724, CEA, BMI, SP (systolic blood pressure), BP (diastolic blood pressure), WHR, HCY, CRP, vitamin $\mathrm{B} 12, \mathrm{Ca}$, and Ghb. Other serum biomarkers were entered into the model as factors using their normal value as the grouping criterion. All the models were adjusted for age as a confounder. A two-tailed $P$-value $<0.05$ was considered to be statistically significant.

\section{Result}

The baseline characteristics of the participants are shown in Table 1 . The mean age was $54.53 \pm 0.238$ years, $167(73.2 \%)$ were male, and $76(26.8 \%)$ were female. Among the study population, 40 (17.5\%) had osteoporosis, 77 (33.8\%) had osteopenia, and 111 (48.7\%) had normal BMDs. The mean ages of the osteoporosis, osteopenia and normal groups were $53.43 \pm 2.836$, $54.53 \pm 3.589$ and $53.98 \pm 3.205$, respectively. There were no significant differences in age among the participants in the osteoporosis, osteopenia and normal BMD groups. Fifty percent of the males had normal BMDs, $34.7 \%$ of the males had osteopenia, and $15.0 \%$ of the males had osteoporosis. In addition, $44.3 \%$ of the females had normal BMDs, $31.1 \%$ of the females had osteopenia, and $24.6 \%$ of the females had osteoporosis. There was no significant difference in sex distribution among these three groups.

Among all the study participants, 35.5\% had H. pylori infections, and $64.5 \%$ did not have $\mathrm{H}$. pylori infections. Table 1 shows that CA724 ( $\mathrm{t}=2.265, P=0.025)$ was significantly different between the study participants with $\mathrm{H}$. pylori infection and those without $\mathrm{H}$. pylori infection, and there were no significant differences between the $\mathrm{H}$. pylori infection status and the BMD status groups.

In Table 2, we separate the study population according to sex. We found that there was a significant relationship between $\mathrm{H}$. pylori infection status and bone density in females $(P=0.025)$ but not in males $(P=0.381)$.

As shown in Table 3 , there was a significant association of $\mathrm{H}$. pylori positivity $(\mathrm{OR}=0.132,95 \% \mathrm{CI}$ $0.023-0.753, P=0.023)$, BMI $(\mathrm{OR}=28.163,95 \% \mathrm{CI}$ $1.647-481.545, \quad P=0.021)$, and $\mathrm{HCY} \quad(\mathrm{OR}=17.218$, 95\% CI 1.061-279.779, $P=0.045)$ with osteoporosis in premenopausal females. $\mathrm{Ca} \quad(\mathrm{OR}=0.060,95 \%$ CI $0.003-1.347, P=0.076)$ and TC $(\mathrm{OR}=7.250,95 \% \mathrm{CI}$ 0.773-68.033, $P=0.076$ ) had a trend, but neither was significantly associated with osteoporosis.

Meanwhile, we analysed the differences in markers between males and females, which are shown in Table 4. We found that age $(P<0.001)$, SP $(P<0.001)$, BP $(P<$ $0.001)$, BMI $(P<0.001)$, WHR $(P<0.001)$, Hb $\quad(P<$ $0.001)$, platelets $(P<0.001)$, UA $(P<0.001)$, TC $(P=$ $0.002)$, TG $(P=0.006)$, HDL-C $(P<0.001)$, GLU $(P=$ 
Table 1 Baseline Characteristics of the patients according to the H. pylori infection statue

\begin{tabular}{|c|c|c|c|c|c|}
\hline \multirow{2}{*}{\multicolumn{2}{|c|}{$\overline{\text { Age }}$}} & \multirow{2}{*}{$\frac{\text { Total }}{54.13 \pm 3.30}$} & \multirow{2}{*}{$\frac{\text { H. pylori- }}{54.02 \pm 3.63}$} & \multirow{2}{*}{$\frac{\text { H. pylori+ }}{54.02 \pm 3.63}$} & \multirow{2}{*}{$\frac{P \text {-value }}{0.887}$} \\
\hline & & & & & \\
\hline \multirow[t]{2}{*}{ Sex } & Female & $26.8 \%$ & $65.6 \%$ & $34.4 \%$ & 0.834 \\
\hline & Male & $73.2 \%$ & $64.1 \%$ & $35.9 \%$ & \\
\hline \multirow[t]{3}{*}{ BMD } & normal & $48.7 \%$ & $48.3 \%$ & $49.4 \%$ & 0.912 \\
\hline & osteopenia & $33.8 \%$ & $34.7 \%$ & $32.1 \%$ & \\
\hline & osteoporosis & $17.5 \%$ & $17.0 \%$ & $18.5 \%$ & \\
\hline \multicolumn{2}{|c|}{$\mathrm{SP}(\mathrm{mmHg})$} & $123.20 \pm 16.802$ & $125.96 \pm 17.772$ & $125.96 \pm 17.772$ & 0.065 \\
\hline \multicolumn{2}{|c|}{$\mathrm{BP}(\mathrm{mmHg})$} & $75.53 \pm 12.494$ & $76.74 \pm 12.350$ & $76.74 \pm 12.350$ & 0.313 \\
\hline \multicolumn{2}{|c|}{ BMI $\left(\mathrm{kg} / \mathrm{m}^{2}\right)$} & $24.752 \pm 3.1597$ & $24.964 \pm 3.350$ & $24.964 \pm 3.350$ & 0.418 \\
\hline \multicolumn{2}{|l|}{ WHR } & $0.901 \pm 0.051$ & $0.902 \pm 0.049$ & $0.902 \pm 0.050$ & 0.920 \\
\hline \multicolumn{2}{|c|}{$\mathrm{Hb}(\mathrm{g} / \mathrm{L})$} & $149.51 \pm 13.397$ & $149.41 \pm 13.825$ & $149.41 \pm 13.825$ & 0.798 \\
\hline \multicolumn{2}{|c|}{ Platelet( $\left.{ }^{*} 10^{9} / \mathrm{L}\right)$} & $236.97 \pm 51.960$ & $234.05 \pm 46.746$ & $234.05 \pm 46.746$ & 0.599 \\
\hline \multicolumn{2}{|c|}{$\mathrm{Ca}(\mathrm{mmol} / \mathrm{L})$} & $2.313 \pm 0.070$ & $2.313 \pm 0.070$ & $2.313 \pm 0.075$ & 0.973 \\
\hline \multicolumn{2}{|c|}{ UA (umol/L) } & $365.61 \pm 81.545$ & $365.37 \pm 85.073$ & $366.05 \pm 75.083$ & 0.910 \\
\hline \multicolumn{2}{|c|}{ TC (mmol/L) } & $4.996 \pm 0.875$ & $4.967 \pm 0.841$ & $5.051 \pm 0.938$ & 0.461 \\
\hline \multicolumn{2}{|c|}{ TG (mmol/L) } & $1.611 \pm 0.920$ & $1.605 \pm 0.947$ & $1.621 \pm 0.874$ & 0.859 \\
\hline \multicolumn{2}{|c|}{$\mathrm{HDL}-\mathrm{C}(\mathrm{mmol} / \mathrm{L})$} & $1.292 \pm 0.286$ & $1.293 \pm 0.284$ & $1.291 \pm 0.292$ & 0.911 \\
\hline \multicolumn{2}{|c|}{ LDL-C (mmol/L) } & $2.685 \pm 0.641$ & $2.661 \pm 0.615$ & $2.731 \pm 0.688$ & 0.354 \\
\hline \multicolumn{2}{|c|}{ GLU (mmol/L) } & $5.519 \pm 1.390$ & $5.392 \pm 1.213$ & $5.754 \pm 1.653$ & 0.063 \\
\hline \multicolumn{2}{|c|}{ CEA (ng/ml) } & $2.549 \pm 1.557$ & $2.430 \pm 1.438$ & $2.771 \pm 1.744$ & 0.103 \\
\hline \multicolumn{2}{|c|}{ CA724(U/ml) } & $3.543 \pm 4.854$ & $4.103 \pm 5.725$ & $2.536 \pm 2.388$ & 0.025 \\
\hline \multicolumn{2}{|c|}{ Ghb(\%) } & $5.838 \pm 1.103$ & $5.767 \pm 0.725$ & $5.966 \pm 1.545$ & 0.307 \\
\hline \multicolumn{2}{|c|}{ Iron (umol/L) } & $19.23 \pm 5.667$ & $19.210 \pm 0.578$ & $19.27 \pm 5.881$ & 0.952 \\
\hline \multicolumn{2}{|c|}{ CRP (mg/L) } & $1.82 \pm 2.430$ & $1.90 \pm 2.557$ & $1.69 \pm 2.199$ & 0.626 \\
\hline \multicolumn{2}{|c|}{ HCY (umol/L) } & $16.187 \pm 7.497$ & $16.518 \pm 8.605$ & $15.592 \pm 4.937$ & 0.486 \\
\hline \multicolumn{2}{|c|}{ B12(pmol/L)) } & $357.61 \pm 185.280$ & $360.07 \pm 190.901$ & $353.20 \pm 176.515$ & 0.834 \\
\hline
\end{tabular}

WHR Waist-to-hip ratio; TC Total cholesterol; Ghb Glycosylated hemoglobin; TG Triglyceride; UA Uric acid; AST Aspartate aminotransferase; ALT Alanine aminotransferase; $\mathrm{Ca}$ Calcium; Cre Creatinine; DP Diastolic blood pressure; Hb Hemoglobin; HDL-C High-density lipoprotein cholesterol; LDL-C Low-density lipoprotein cholesterol; BMD Bone mineral density; OR Odds ratio; proGRP Pro-gastrin-releasing peptide; WHR Waist-to-Hip Ratio; SP Systolic blood pressure; PG Pepsinogen; GLU Glucose; CRP C-reactive protein; HCY HOMOCYSTEINE;

Bold indicates statistically significant values

Table 2 the relationship between the H. pylori infection and the BMD in different gender

\begin{tabular}{llll}
\hline Female & & & \\
\hline & H. pylori infection (-) & H. pylori infection $(+)$ & $P$-value \\
Normal BMD & 18 & 9 & $\mathbf{0 . 0 2 5}$ \\
osteopenia & 16 & 4 & \\
osteoporosis & 6 & 9 & \\
Male & & & \\
& H. pylori infection $(+)$ & H. pylori infection $(-)$ & $P$-value \\
Normal BMD & 53 & 31 & 0.381 \\
osteopenia & 35 & 23 & \\
osteoporosis & 19 & 6 &
\end{tabular}

$B M D$ Bone mineral density;

Bold indicates statistically significant values
0.002), CEA $(P<0.001)$, Ghb $(P=0.029)$, iron $(P<0.001)$, HCY $(P<0.001)$, and B12 $(P=0.002)$ demonstrated significant differences between males and females.

The relationship between sex and markers is shown in Table 5. We found that WHR $(\mathrm{OR}=5.783,95 \% \mathrm{CI}$ $1.192-28.078, \quad P=0.029), \quad$ TG $\quad(\mathrm{OR}=0.201, \quad 95 \% \quad \mathrm{CI}$ $0.045-0.902, P=0.036)$, and BMI $(\mathrm{OR}=0.152,95 \% \mathrm{CI}$ $0.034-0.688, P=0.014$ ) were significantly different by sex, adjusting for age as a confounder.

\section{Discussion}

Osteoporosis is an important health and societal burden in elderly people, not only in females but also in males. There are numerous osteoporosis-related fracture risk factors, including age, sex, race, lifestyle and concomitant medical conditions [16]. In men, osteoporosis is underrecognized and undertreated. Only a few men are 
Table 3 Multivariable analysis for different markers and BMD

\begin{tabular}{|c|c|c|c|}
\hline & OR & $95 \% \mathrm{Cl}$ & $P$-value \\
\hline \multicolumn{4}{|l|}{$\mathrm{TC}(\mathrm{mmol} / \mathrm{L})$} \\
\hline Q1(3.65-5.20) & 7.250 & $0.773,68.033$ & 0.083 \\
\hline Q2(5.21-7.66) & 0 & 0 & \\
\hline \multicolumn{4}{|l|}{ BMI $\left(\mathrm{kg} / \mathrm{m}^{2}\right)$} \\
\hline Q1(17.9-23.9) & 28.163 & $1.647,481.545$ & 0.021 \\
\hline Q2(24.0-31.9) & 0 & 0 & \\
\hline \multicolumn{4}{|l|}{ UA (umol/L) } \\
\hline Q1(187-357) & 0.324 & $0.028,3.827$ & 0.371 \\
\hline Q2(358-571) & 0 & 0 & \\
\hline \multicolumn{4}{|l|}{ TG (mmol/L) } \\
\hline Q1(0-1.70) & 0.162 & $0.009,2.858$ & 0.214 \\
\hline Q2(1.71-4.47) & 0 & 0 & \\
\hline \multicolumn{4}{|l|}{ LDL-C (mmol/L) } \\
\hline $\mathrm{Q} 1(0-3.12)$ & 0.273 & $0.029,2.524$ & 0.252 \\
\hline Q2(3.13-4.20) & 0 & 0 & \\
\hline \multicolumn{4}{|l|}{ C13 } \\
\hline Q1(without H. pylor) & 0.132 & $0.023,0.753$ & 0.023 \\
\hline Q2(with H. pylor) & 0 & 0 & \\
\hline \multicolumn{4}{|l|}{ WHR } \\
\hline Q1(0.79-0.84) & 3.529 & $0.472,26.390$ & 0.219 \\
\hline Q2(0.85-0.97) & 0 & 0 & \\
\hline \multicolumn{4}{|l|}{$\mathrm{HCY}$} \\
\hline Q1 $(0-14.9 \mu \mathrm{mol} / \mathrm{L})$ & 17.218 & $1.061,279.779$ & 0.045 \\
\hline $\mathrm{Q} 2(>15 \mu \mathrm{mol} / \mathrm{L})$ & 0 & 0 & 0 \\
\hline \multicolumn{4}{|l|}{ CRP } \\
\hline Q1 (0-4.9 mg/L) & 0.167 & $0.001,32.917$ & 0.507 \\
\hline $\mathrm{Q} 2$ (> $5 \mathrm{mg} / \mathrm{L})$ & 0 & 0 & \\
\hline \multicolumn{4}{|l|}{$\mathrm{Ca}$} \\
\hline Q1 (2.1-2.25 mg/L) & 0.060 & $0.003,1.347$ & 0.076 \\
\hline $\mathrm{Q} 1$ (> $2.25 \mathrm{mg} / \mathrm{L})$ & 0 & 0 & \\
\hline \multicolumn{4}{|l|}{ B12 } \\
\hline Q1(0-516pmol/L) & 0.228 & $0.706,54.927$ & 0.100 \\
\hline $\mathrm{Q} 2(>516 \mathrm{pmol} / \mathrm{L})$ & 0 & 0 & \\
\hline
\end{tabular}

Abbreviations as in Table 1; OR Odds ratio; $\mathrm{C} 13{ }^{13} \mathrm{C}$ breathing test positive; Bold indicates statistically significant values

screened for osteoporosis, even after a fracture [17]. The treatment rate is much lower in males than in females [18]. Meanwhile, more men than women die every year due to hip fractures [19]. Hence, we also included men in the study population to determine the risk factors for osteoporosis.

Some studies about the influence of sex on osteoporosis remain controversial. In our study, there was a significant relationship between $\mathrm{H}$. pylori and osteoporosis in premenopausal females but not in males. The reasons for the difference between males and females are as follows: First, differences in clinical outcomes of osteoporosis in men and women may be rooted in the biologic properties of bone. Barrett-Connor $\mathrm{E}$ holds the view that there are sex-specific differences in the number of osteoprogenitor cells and in hormone responses and regulation [20,21]. Second, men have a greater bone size, trabecular BMD and bone area at the radius and tibia than women, even after adjusting for weight and height, which may lead to a decrease in osteoporosis and fracture [22]. Third, men undergo a slow decrease in BMD with increasing age, while women experience a profound period of rapid bone resorption, especially after entering menopause [23]. Last but not least, some studies support the idea that men are more likely to suffer from secondary disease, for example, rheumatoid arthritis, alcoholism, excessive smoking, gonadal deficiencies and others [24], which may lead to sustainable bone loss.

Unfortunately, the relationship between osteoporosis and $\mathrm{H}$. pylori infection is still controversial. Some studies hold the view that there is no difference between men and women in the relationship between $\mathrm{H}$. pylori and osteoporosis $[25,26]$. Some studies hold the view that $\mathrm{H}$. pylori is related to osteoporosis only in women. ShihChun Lin conducted a retrospective study including 365 women and showed that $\mathrm{H}$. pylori is related to osteoporosis in females [27], while others think that there is no correlation between them in females. Daisuke Chinda conducted a study of 473 healthy women and found that $\mathrm{H}$. pylori is not a significant risk factor for osteopenia [28]. In our study, we analysed the relationship between $\mathrm{H}$. pylori infection and osteoporosis. We found a significant relationship between $\mathrm{H}$. pylori infection status and bone density in premenopausal females but not in males. We suspect this may be due to the difference in the aetiology of osteoporosis between males and females. However, we did not find any other studies on this, and it requires more systematic research for analysis.

After analysing the differences between males and females, we found that there were significant differences in BMI, WHR, and TG in the study population. This study provides evidence for follow-up research on sex differences in the relationship between $\mathrm{H}$. pylori and osteoporosis.

Most studies hold the view that obesity is related to osteoporosis [29]. It is generally believed that obesity may be a protective factor against bone loss and osteoporosis [30]. However, the effect of obesity remains unclear. On the one hand, obesity has traditionally been considered positive for bone because of the beneficial effect of mechanical loading [31]. On the other hand, people hold the view that BMI may harm BMD. Osteoblasts and adipocytes both stem from marrow mesenchymal stromal cells. Osteoblasts and adipocytes are in a 
Table 4 Baseline Characteristics of the patients in different gender

\begin{tabular}{|c|c|c|c|c|}
\hline & Total & Female & Male & $P$-value \\
\hline Age & $54.13 \pm 3.304$ & $52.23 \pm 1.865$ & $54.74 \pm 3.441$ & 0.000 \\
\hline $\mathrm{SP}(\mathrm{mmHg})$ & $123.20 \pm 16.802$ & $112.79 \pm 15.598$ & $126.87 \pm 15.767$ & 0.000 \\
\hline $\mathrm{BP}(\mathrm{mmHg})$ & $75.53 \pm 12.494$ & $66.05 \pm 11.273$ & $79.06 \pm 10.966$ & 0.000 \\
\hline BMI $\left(\mathrm{kg} / \mathrm{m}^{2}\right)$ & $24.752 \pm 3.1597$ & $23.016 \pm 3.104$ & $25.336 \pm 2.975$ & 0.000 \\
\hline WHR & $0.901 \pm 0.051$ & $0.880 \pm 0.039$ & $0.911 \pm 0.053$ & 0.001 \\
\hline $\mathrm{Hb}(\mathrm{g} / \mathrm{L})$ & $149.51 \pm 13.397$ & $135.79 \pm 10.965$ & $154.80 \pm 9.995$ & 0.000 \\
\hline Platelet( $\left.{ }^{*} 10^{9} / \mathrm{L}\right)$ & $236.97 \pm 51.960$ & $255.21 \pm 51.091$ & $229.67 \pm 47.700$ & 0.001 \\
\hline $\mathrm{Ca}(\mathrm{mmol} / \mathrm{L})$ & $2.313 \pm 0.070$ & $2.317 \pm 0.081$ & $2.311 \pm 0.064$ & 0.622 \\
\hline UA (umol/L) & $365.61 \pm 81.545$ & $307.05 \pm 67.596$ & $386.49 \pm 73.515$ & 0.000 \\
\hline TC (mmol/L) & $4.996 \pm 0.875$ & $5.335 \pm 0.899$ & $4.868 \pm 0.835$ & 0.000 \\
\hline TG (mmol/L) & $1.611 \pm 0.920$ & $1.331 \pm 0.754$ & $1.706 \pm 0.963$ & 0.006 \\
\hline $\mathrm{HDL}-\mathrm{C}(\mathrm{mmol} / \mathrm{L})$ & $1.292 \pm 0.286$ & $1.453 \pm 0.267$ & $1.235 \pm 0.274$ & 0.000 \\
\hline LDL-C (mmol/L) & $2.685 \pm 0.641$ & $2.794 \pm 0.638$ & $2.636 \pm 0.631$ & 0.096 \\
\hline GLU (mmol/L) & $5.519 \pm 1.390$ & $5.153 \pm 0.742$ & $5.631 \pm 1.519$ & 0.002 \\
\hline CEA (ng/ml) & $2.549 \pm 1.557$ & $1.934 \pm 1.119$ & $2.768 \pm 1.632$ & 0.000 \\
\hline CA724(U/ml) & $3.543 \pm 4.854$ & $3.742 \pm 3.209$ & $3.449 \pm 5.477$ & 0.740 \\
\hline Ghb(\%) & $5.838 \pm 1.103$ & $5.618 \pm 0.424$ & $5.942 \pm 1.296$ & 0.029 \\
\hline Iron (umol/L) & $19.23 \pm 5.667$ & $16.90 \pm 5.521$ & $20.33 \pm 5.421$ & 0.001 \\
\hline CRP (mg/L) & $1.82 \pm 2.430$ & $1.52 \pm 1.626$ & $1.97 \pm 2.732$ & 0.302 \\
\hline $\mathrm{HCY}$ (umol/L) & $16.187 \pm 7.497$ & $12.887 \pm 2.947$ & $17.751 \pm 8.448$ & 0.000 \\
\hline B12(pmol/L)) & $357.61 \pm 185.280$ & $439.11 \pm 221.573$ & $319.01 \pm 151.975$ & 0.002 \\
\hline
\end{tabular}

Abbreviations as in Table 1; OR Odds ratio;

Bold indicates statistically significant values

competitive relationship, and an increase in adipocytes will inhibit osteoblasts [30]. In our study, there was a significant relationship between BMI and osteoporosis. Increased BMD levels in obese people may be associated with increased mechanical loading and strain; this is a complicated problem that cannot be generalized.

In our study, we found that $\mathrm{H}$. pylori infection is associated with a decrease in bone density. The possible reasons are as follows: First, H. pylori infection may cause systemic inflammation and increase the production of tumour necrosis factor- $\alpha$, interleukin-1, and interleukin6 [11]. These cytokines are directly involved in the reduction of BMD. We found that HCY is related to osteoporosis, which supports this hypothesis. Second, osteoporosis may be related to a decrease in vitamin B12 levels [32]. Serin et al.'s study examined 145 patients without atrophy, erosions or ulcers, and they found that the histopathological scores for both antral and corpus $\mathrm{H}$. pylori density and inflammation were significantly inversely associated with serum vitamin B12 levels [13]. In our study, although we did not find a significant relationship between B12 and osteoporosis, we still support the relevant theory. The absence of our results may be due to a lack of sufficient data and the influence of confounding factors. Last but not least, most patients chronically infected with $\mathrm{H}$. pylori manifest pangastritis with reduced acid secretion due to bacterial virulence factors, inflammatory cytokines, and various degrees of gastric atrophy [33]. Calcium is ionized in acidic conditions and absorbed in the small bowel. Therefore, in either hypochlorhydria or achlorhydric stomachs, calcium absorption is impaired [12]. Moreover, the long-term use of acid suppressants, for example, proton pump inhibitors, may lead to osteoporosis or a decrease in BMD. Limited experimental evidence indicates that PPI may influence calcium absorption, leading to compensatory physiologic responses, including secondary hyperparathyroidism, which may cause an increase in the rate of osteoclastic bone resorption [34]. The results showed that calcium had a trend, though it was not statistically significant $(P=0.076)$, with osteoporosis. Our results do not support the theory that there is a correlation between $\mathrm{Ca}$ and osteoporosis, but it may be that Helicobacter pylori infection may cause calcium absorption damage and affect BMD. We did not analyse vitamin D levels, which could affect both bone homeostasis and the inflammatory state [35]. Although H. pylori infection causing a decrease in bone density is supported by most researchers, the effect of early eradication therapy is still insufficient. Replogle ML holds the view that early 
Table 5 Multivariable analysis for different markers and gender

\begin{tabular}{|c|c|c|c|}
\hline & OR & $95 \% \mathrm{Cl}$ & $P$-value \\
\hline \multicolumn{4}{|l|}{ WHR } \\
\hline Q1(0.79-0.84) & 5.783 & $1.192,28.078$ & 0.029 \\
\hline Q2(0.85-0.97) & 0 & 0 & \\
\hline \multicolumn{4}{|l|}{ TC (mmol/L) } \\
\hline $\mathrm{Q} 1(0-5.20)$ & 1.694 & $0.345,8.298$ & 0.516 \\
\hline $\mathrm{Q} 2(>5.21)$ & 0 & 0 & \\
\hline \multicolumn{4}{|l|}{ LDL-C (mmol/L) } \\
\hline $\mathrm{Q} 1(0-3.12)$ & 2.502 & $0.374,16.710$ & 0.344 \\
\hline Q2(3.13-4.52) & 0 & 0 & \\
\hline \multicolumn{4}{|l|}{ UA (umol/L) } \\
\hline Q1(187-357) & 1.096 & $0.246,4.884$ & 0.904 \\
\hline Q2(358-571) & 0 & 0 & \\
\hline \multicolumn{4}{|l|}{ TG (mmol/L) } \\
\hline Q1(0-1.70) & 0.201 & $0.045,0.902$ & 0.036 \\
\hline Q2(1.71-13.19) & 0 & 0 & \\
\hline \multicolumn{4}{|l|}{ GLU (mmol/L) } \\
\hline $\mathrm{Q} 1(0-6.10)$ & 0.584 & $0.072,4.740$ & 0.615 \\
\hline Q2(6.11-13.03) & 0 & 0 & \\
\hline \multicolumn{4}{|l|}{ CA724(U/ml) } \\
\hline Q1(0-6.89) & 2.787 & $0.481,16.151$ & 0.253 \\
\hline Q2(6.90-39.18) & 0 & 0 & \\
\hline \multicolumn{4}{|l|}{ CEA (ng/ml) } \\
\hline Q1(0-4.99) & 0.211 & $0.013,3.511$ & 0.278 \\
\hline Q2(5.00-9.85) & 0 & 0 & \\
\hline \multicolumn{4}{|l|}{$\mathrm{BMI}\left(\mathrm{kg} / \mathrm{m}^{2}\right)$} \\
\hline Q1(17.9-23.9) & 0.152 & $0.034,0.688$ & 0.014 \\
\hline Q2(24.0-34.1) & 0 & 0 & \\
\hline \multicolumn{4}{|l|}{$\mathrm{SP}(\mathrm{mmHg})$} \\
\hline Q1(90-140) & 0.133 & $0.005,3.228$ & 0.215 \\
\hline $\mathrm{Q} 2(>140)$ & 0 & 0 & \\
\hline \multicolumn{4}{|l|}{$\mathrm{BP}(\mathrm{mmHg})$} \\
\hline Q1(60-90) & 1.119 & $0.057,21.889$ & 0.914 \\
\hline $\mathrm{Q} 2(>90)$ & 0 & 0 & \\
\hline \multicolumn{4}{|l|}{$\mathrm{HCY}(\mu \mathrm{mol} / \mathrm{L})$} \\
\hline Q1(0-14.9) & 0.377 & $0.091,1.559$ & 0.178 \\
\hline $\mathrm{Q} 2(>15)$ & 0 & 0 & \\
\hline \multicolumn{4}{|l|}{ CRP (mg/L) } \\
\hline Q1 (0-4.9) & 4.076 & $0.289,57.397$ & 0.298 \\
\hline Q2 (>5) & 0 & 0 & \\
\hline \multicolumn{4}{|l|}{ B12(pmol/L) } \\
\hline Q1(0-516) & 6.038 & $0.681,53.464$ & 0.106 \\
\hline $\mathrm{Q} 2(>516)$ & 0 & 0 & \\
\hline \multicolumn{4}{|l|}{$\mathrm{Ca}(\mathrm{mg} / \mathrm{L})$} \\
\hline Q1 (2.1-2.25) & 1.502 & $0.327,6.903$ & 0.601 \\
\hline
\end{tabular}


Table 5 Multivariable analysis for different markers and gender (Continued)

\begin{tabular}{clll}
\hline & OR & $95 \% \mathrm{Cl}$ & $P$-value \\
\hline Q1 (>2.25) & 0 & 0 \\
Ghb(\%) & & \\
Q1(0-6.0) & 0.487 & $0.064,3.691$ & 0.487 \\
Q2(6.1-7.3) & & \\
\hline
\end{tabular}

Abbreviations as in Table 1; OR Odds ratio;

Bold indicates statistically significant values

Male and female have different normal value in UA and WHR, UA 149-416umol/L in male,89-357umol/L in female, WHR $<9.0$ in male, $<8.5$ in female

eradication therapy may eliminate chronic inflammation from H. pylori [36]. Some articles have also reported an improvement in B12 levels after complete eradication $[13,37]$, which requires further investigation.

Despite its relevant findings, our study had several limitations. First, because most patients cannot remember the time of HP infection accurately, we were not able to obtain the time of HP infection, so different infection times may have had an impact on the results. Second, we did not collect vitamin D data, the sample size of our data was not large enough, and the study population only included participants from Beijing Shijitan Hospital, meaning that there might have confounding factors because of differences in the distribution of hospital study populations. Further large-scale studies in the general population are needed to validate our results. Third, the study participants were all Chinese, and the findings might not be generalizable to other ethnic populations. In addition, we only found some differences between men and women but failed to further explore them.

\section{Conclusions}

$\mathrm{H}$. pylori is associated with osteoporosis in premenopausal females. BMI and HCY are related to osteoporosis in premenopausal females. Chronic inflammation may be involved in the relationship between $\mathrm{H}$. pylori and osteoporosis.

\section{Supplementary information}

Supplementary information accompanies this paper at https://doi.org/10. 1186/s12891-020-03586-7.

Additional file 1.

\section{Abbreviations}

DXA: Lumbar dual-energy x-ray absorptiometry; ORs: Odds ratios; Cls: Confidence intervals; H. pylori: Helicobacter pylori; SERMs: Selective estrogen receptor modulators; proGRP: Pro-gastrin-releasing peptide; BMI: Body mass index; WHR: Waist-to-hip ratio; BMD: Bone mineral density; WHO: World health organization; SD: Standard deviation; TC: Total cholesterol; TG: Triglycerides; UA: Uric acid; LDL-C: Low-density lipoprotein cholesterol; Ghb: Glycosylated haemoglobin; HDL-C: High-density lipoprotein cholesterol; GLU: Glucose; PG: Pepsinogen; CA: Calcium; DP: Diastolic blood pressure; Hb: Haemoglobin; SP: Systolic blood pressure; $\mathrm{C} 13:{ }^{13} \mathrm{C}$ breathing test positive
}

Acknowledgements

Not applicable.

\section{Authors' contributions}

LH has made substantial contributions to the design of the work; SSJ has provided the data, obtained the consent of participants and analyzed the data preliminarily; ZLC has made contributions to the collection of data and participated in the drafting of the article; DFX has analyzed and interpreted of the data; WJW has drafted the manuscript;SH has helped to revise the manuscript. All authors have read and approved the manuscript.

\section{Funding}

The study was supported by a program from the Beijing City Health System "215" High Levels of Health Technical Personnel Training Aid and the Capital Clinical Characteristic Applied Research Project (No.Z181100001718120).

Funds are used for the data collection portion.

\section{Availability of data and materials}

The datasets analyzed during the current study are not publicly available because it includes the study population personal information which is illegal to open but are available from the corresponding author on reasonable request.

Ethics approval and consent to participate

All the ethics approval has been given by the ethics committee of Beijing shijitan hospital affiliated to capital medical university and have been performed in accordance with the Declaration of Helsinki. We used the participants data by anonymous. All involved study populations were from the previous physical examination group and part of the population are not in Beijing. All the participants received the informed consent by email. We read informed consent to patients or their immediate family members by telephone and inform them of the purpose and significance of the study, and obtain their oral consent, which is approved by the ethics committee.

\section{Consent for publication}

Not applicable.

\section{Competing interests}

The authors declare that they have no competing interests in this section.

\section{Author details}

${ }^{1}$ Department of Gastroenterology, Beijing Shijitan Hospital, Capital Medical University, No. 10, Tieyi Road, Beijing, China. ${ }^{2}$ Department of Physical examination center, Beijing Shijitan Hospital, Capital Medical University, No. 10, Tieyi Road, Beijing, China. ${ }^{3}$ Department of Gastroenterology, Beijing Shijitan Hospital, Capital Medical University Beijing, Beijing 100038, China.

Received: 12 March 2020 Accepted: 13 August 2020

Published online: 18 August 2020

\section{References}

1. Glaser DL, Kaplan FS. Osteoporosis: Definition and clinical presentation. Spine (Phila Pa 1976). 1997;22(24 Suppl):12s-6s.

2. Malfertheiner P, Megraud F, O'Morain CA, Atherton J, Axon AT, Bazzoli F, et al. Management of Helicobacter pylori infection--the Maastricht IV/ Florence consensus report. Gut. 2012;61(5):646-64. 
3. Matsuhisa T, Aftab H. Observation of gastric mucosa in Bangladesh, the country with the lowest incidence of gastric cancer, and Japan, the country with the highest incidence. Helicobacter. 2012;17(5):396-401.

4. Upala S, Jaruvongvanich V, Riangwiwat T, Jaruvongvanich S, Sanguankeo A. Association between helicobacter pylori infection and metabolic syndrome: a systematic review and meta-analysis. J Dig Dis. 2016:17(7):433-40.

5. Tang DM, Kumar S. The association between helicobacter pylori infection and nonalcoholic fatty liver disease. Curr Gastroenterol Rep. 2017;19(2):5.

6. Smyk DS, Koutsoumpas AL, Mytilinaiou MG, Rigopoulou El, Sakkas LI, Bogdanos DP. Helicobacter pylori and autoimmune disease: cause or bystander. World J Gastroenterol. 2014;20(3):613-29.

7. Office of the Surgeon G. Reports of the Surgeon General. Bone Health and Osteoporosis: A Report of the Surgeon General. Rockville (MD): Office of the Surgeon General (US); 2004.

8. Nguyen ND, Ahlborg HG, Center JR, Eisman JA, Nguyen TV. Residual lifetime risk of fractures in women and men. J Bone Miner Res. 2007;22(6):781-8.

9. Haentjens P, Magaziner J, Colon-Emeric CS, Vanderschueren D, Milisen K Velkeniers B, et al. Meta-analysis: excess mortality after hip fracture among older women and men. Ann Intern Med. 2010;152(6):380-90.

10. Yoshimura N, Suzuki T, Hosoi T, Orimo H. Epidemiology of hip fracture in Japan: incidence and risk factors. J Bone Miner Metab. 2005:23(Suppl):78-80.

11. Chung YH, Gwak JS, Hong SW, Hyeon JH, Lee CM, Oh SW, et al. Helicobacter pylori: a possible risk factor for bone health. Korean J Fam Med. 2015;36(5):239-44.

12. Recker RR. Calcium absorption and achlorhydria. N Engl J Med. 1985;313(2): 70-3.

13. Serin E, Gumurdulu Y, Ozer B, Kayaselcuk F, Yilmaz U, Kocak R. Impact of helicobacter pylori on the development of vitamin B12 deficiency in the absence of gastric atrophy. Helicobacter. 2002;7(6):337-41.

14. Tyagi NK, Dhesy-Thind S. Clinical practice guidelines in breast cancer. Curr Oncol. 2018;25(Suppl 1):S151-s60.

15. Kanis JA, Melton LJ 3rd, Christiansen C, Johnston CC, Khaltaev N. The diagnosis of osteoporosis. J Bone Miner Res. 1994;9(8):1137-41.

16. Dontas IA, Yiannakopoulos CK. Risk factors and prevention of osteoporosisrelated fractures. J Musculoskelet Neuronal Interact. 2007;7(3):268-72.

17. Gennari L, Bilezikian JP. New and developing pharmacotherapy for osteoporosis in men. Expert Opin Pharmacother. 2018;19(3):253-64.

18. Bougioukli S, Kollia P, Koromila T, Varitimidis S, Hantes M, Karachalios T, et al. Failure in diagnosis and under-treatment of osteoporosis in elderly patients with fragility fractures. J Bone Miner Metab. 2019:37(2):327-35.

19. Alejandro $P$, Constantinescu F. A review of osteoporosis in the older adult: an update. Rheum Dis Clin N Am. 2018;44(3):437-51.

20. McMillan J, Fatehi-Sedeh S, Sylvia VL, Bingham V, Zhong M, Boyan BD, et al. Sex-specific regulation of growth plate chondrocytes by estrogen is via multiple MAP kinase signaling pathways. Biochim Biophys Acta. 2006; 1763(4):381-92.

21. Lenart BA, Neviaser AS, Lyman S, Chang CC, Edobor-Osula F, Steele B, et al. Association of low-energy femoral fractures with prolonged bisphosphonate use: a case control study. Osteoporos Int. 2009;20(8):135362.

22. Ho-Pham LT, Ho-Le TP, Mai LD, Do TM, Doan MC, Nguyen TV. Sex-difference in bone architecture and bone fragility in Vietnamese. Sci Rep. 2018;8(1) 7707.

23. Clarke BL, Khosla S. Physiology of bone loss. Radiol Clin N Am. 2010;48(3): 483-95

24. Hofbauer LC, Hamann C, Ebeling PR. Approach to the patient with secondary osteoporosis. Eur J Endocrinol. 2010;162(6):1009-1020.

25. Asaoka D, Nagahara A, Hojo M, Sasaki H, Shimada Y, Yoshizawa T, et al. The Relationship between $\mathrm{H}$ pylori Infection and Osteoporosis in Japan. Gastroenterol Res Pract. 2014;2014:340765.

26. Asaoka D, Nagahara A, Shimada Y, Matsumoto K, Ueyama H, Matsumoto K, et al. Risk factors for osteoporosis in Japan: is it associated with helicobacter pylori? Ther Clin Risk Manag. 2015;11:381-91.

27. Lin SC, Koo M, Tsai KW. Association between helicobacter pylori infection and risk of osteoporosis in elderly Taiwanese women with upper gastrointestinal diseases: a retrospective patient record review. Gastroenterol Res Pract. 2014;2014:814756

28. Chinda D, Shimoyama T, lino C, Matsuzaka M, Nakaji S, Fukuda S. Decrease of estradiol and several lifestyle factors, but not helicobacter pylori infection, are significant risks for osteopenia in Japanese females. Digestion. 2017; 96(2):103-9.
29. Pan B-L, Huang C-F, Chuah S-K, Chiang J-C, Loke S-S. Relationship between Helicobacter pylori infection and bone mineral density: a retrospective cross-sectional study. BMC Gastroenterol. 2018;18(1):54.

30. Głogowska-Szelag J, Szeląg M, Stolecki M, Kudła M. Obesity and osteoporosis-connections between adipose tissue and bone. Wiad Lek. 2019;72(9 cz 2):1834-8.

31. Fassio A, Idolazzi L, Rossini M, Gatti D, Adami G, Giollo A, et al. The obesity paradox and osteoporosis. Eat Weight Disord. 2018;23(3):293-302.

32. Tucker KL, Hannan MT, Qiao N, Jacques PF, Selhub J, Cupples LA, et al. Low plasma vitamin B12 is associated with lower BMD: the Framingham osteoporosis study. J Bone Miner Res. 2005;20(1):152-8.

33. Smolka AJ, Schubert ML. Helicobacter pylori-induced changes in gastric acid secretion and upper gastrointestinal disease. Curr Top Microbiol Immunol. 2017;400:227-52.

34. Wright MJ, Proctor DD, Insogna KL, Kerstetter JE. Proton pump-inhibiting drugs, calcium homeostasis, and bone health. Nutr Rev. 2008;66(2):103-8.

35. Bellavia D, Costa V, De Luca A, Maglio M, Pagani S, Fini M, et al. Vitamin D level between calcium-phosphorus homeostasis and immune system: new perspective in osteoporosis. Curr Osteoporos Rep. 2016.

36. Shih HM, Hsu TY, Chen CY, Lin CL, Kao CH, Chen CH, et al.Analysis of Patients with Helicobacter pylori Infection and the Subsequent Risk of Developing Osteoporosis after Eradication Therapy: A Nationwide Population-Based Cohort Study. PLoS One. 2016;11(9):e0162645. Published 2016 Sep 14. https://doi.org/10.1371/journal.pone.0162645.

37. Avcu N, Avcu F, Beyan C, Ural AU, Kaptan K, Ozyurt M, et al. The relationship between gastric-oral helicobacter pylori and oral hygiene in patients with vitamin B12-deficiency anemia. Oral Surg Oral Med Oral Pathol Oral Radiol Endod. 2001;92(2):166-9.

\section{Publisher's Note}

Springer Nature remains neutral with regard to jurisdictional claims in published maps and institutional affiliations.

Ready to submit your research? Choose BMC and benefit from:

- fast, convenient online submission

- thorough peer review by experienced researchers in your field

- rapid publication on acceptance

- support for research data, including large and complex data types

- gold Open Access which fosters wider collaboration and increased citations

- maximum visibility for your research: over $100 \mathrm{M}$ website views per year

At $\mathrm{BMC}$, research is always in progress.

Learn more biomedcentral.com/submission 